\title{
TANGO AS THE EPISTEME OF LATIN AMERICAN CULTURAL UNIVERSUM IN THE POETIC FANTASY OF THE RUSSIAN EMIGRANT POET ANDREI SHIRIAEV
}

\section{ТАНГО КАК ЭПИСТЕМА ЛАТИНОАМЕРИКАНСКОГО КУЛЬТУРНОГО УНИВЕРСУМА В ПОЭТИЧЕСКОЙ ФАНТАЗИИ РУССКОГО ПОЭТА-ЭМИГРАНТА АНДРЕЯ ШИРЯЕВА}

\section{Svetlana Fokina ${ }^{1}$}

DOI: https://doi.org/10.30525/978-9934-26-021-6-2

Abstract. The relevance of the lifted problem is caused as the interest of a modern philological thought in a phenomenon of the writer emigrant, and attention in aspects of Dionysian attitudes of literary artists. In the article research search is directed to studying of A. Shiryaev's interpretation of the tango phenomenon as the semiosis of passion and the epistem of Argentine culture. The open process represents at this stage the knowledge of the poetic heritage of the modern emigrant poet A. Shiryaev and requires close attention. The subject of analysis was the process of a mythologization by poetic consciousness of the poet emigrant of history of tragic death of the legendary performer of a tango Carlos Gardel. A. Shiryaev is creates the author's version of the myth about an idol of Argentina. The novelty of the presented material is due to the lack of study of strategies for identifying the author's consciousness of A. Shiryaev as an emigrant poet in the framework of the mastery of mythology and epistles of Latin American culture. The methodology of the study was the establishment of the poet's author's myth about the search for self-identification. The purpose of article is to reveal as in poem by A. Shiryaev «The Creole Thrush Sings Better and Better Every Day...» under construction as paraphrases of the glorified and tragic biography of Carlos Gardel. Reading of author's connotations is presented to interpretations of an image of the female phantom - madam

\footnotetext{
${ }^{1}$ Candidate of Philological Sciences, Doctoral Candidate,

Associate Professor at Department of General and Slavic Literature,

Odessa I.I. Mechnikov National University, Ukraine
} 
Ivonne. The emphasized sexuality of Madame Ivonne is supplemented by the transformation of erotic codes into gastronomic codes. This subtext level is something like the author's comment. In the Shiryaev poetic fantasy, the metaphor of cannibalism is realized almost literally as an opportunity to eat Madame Ivonne the «flesh» of the burned Gardel. This aspect highlights demonic connotations in heroin, emphasizing the theme of vampirism. The study made it possible to draw the following conclusions. Pronounced metaphorical potential of lyrics of A. Shiryaev is the evidence of proximity author's consciousness of the poet emigrant of elements mysteriological Dionysian a discourse. The poetic myth by A. Shiryaev is characterized by proximity to Dionysian type of attitude and the transgressive nature of author's consciousness of the poet emigrant.

\section{1. Введение}

Актуальность поставленной проблемы связана с интересом современного литературоведения к феномену писателей- и поэтов-эмигрантов, к своеобразию их самоидентификации и авторского мифа.

Изученность поэтического наследия современного поэта-эмигранта А. Ширяева представляет на данном этапе открытый процесс и требует пристального внимания. В предшествующих статьях автора данного исследования были осуществлены попытки прочтения ширяеского поэтического текста. В частности было осмыслено «включение феномена танго и представлений о Карлосе Гарделе в авторский миф» [22, с. 279] А. Ширяева. Представлен анализ диалога поэта-эмигранта с Серебряным веком в плане выявления аллюзивных пластов, которые «проявляются в ширяевском поэтическом тексте на уровне неточных, но вполне узнаваемых и даже эмблематических цитат» [23, с. 178]. Предложена интерпретация процессов сакрализации и демонизации, показателями чего является тот факт, что «А. Ширяев создает не только миф о Гарделе как трагически гибнущем культурном герое, но поливалентно моделирует и женский образ-призрак...» [24, с. 117]. Новизна представленного материала обусловлена недостаточностью изученности стратегий идентификации авторского сознания А. Ширяева как поэта-эмигранта в рамках освоения мифологем и эпистем латиноамериканской культуры.

Цель - проанализировать танго как культурную эпистему и смысло-эмоциональный мифогенный комплекс в поэтическом тексте 
А. Ширяева «Креольский дрозд поёт всё лучше с каждым днём...». Задачи: 1) проследить процесс мифологизации поэтическим сознанием поэта-эмигранта образа легендарного певца танго Карлоса Гарделя в контексте эпистемологических доминант латиноамериканского культурного универсума; 2) рассмотреть процесс конструирования образа-фантома мадам Ивонн как воплощение роковой женщины и анимы лирического субъекта; 3) осмыслить символику пожирания как знаковый смысловой пласт подтекста ширяевского стихотворения.

Методологические основы данного исследования обусловлены традициями изучения различных феноменов, прояснение культурной и семиотической специфики которых, было задано необходимостью дешифровки вех ширяевского лирического сюжета. К знаковым кодам и комплексам, определившим логику исследования, относятся представления о латиноамериканском этосе (Ю. Гирин), культуре танго (Х. Л. Борхес, Ю. Гирин, П. Пичугин), феномене Карлоса Гарделя (X. Кортасар), статегиях идентичности (С. Бурини), пограничности и переходности (Ю. Лотман, Т. Цивьян, Е. Фарыно, Х. Эйзенфелд), имидже роковой женщины (Р. Барт, Ж. Старобинский, О. Матич, К. Богданов), сакральности (С. Зенкин), демонологии (Е. Махов), дионисийском дискурсе (О. Ханзен-Лёве), метафоре каннибализма (3. Фрейд, Ж. Лапланш, Ж.- Б. Понталис, К. Леви-Стросс,) семиотике страстей (А. Ж. Греймас, Ж. Фонтаний), эротическом дискурсе (Д. Иоффе). Стратегии анализа в соответствии с вышеуказанными исследовательскими установками были направлены на изучение «аргентинского» лирического сюжета А. Ширяева с соответствующим семиозисом страстей, дискурсивных контекстов и идентификационных практик.

\section{2. Стратегии идентификации русского поэта-эмигранта с миром Латинской Америки}

Создание авторского мифа А. Ширяевым как поэтом-эмигрантом отличает тенденция обыгрывания разных моделей идентичности.

Стихотворение А. Ширяева «Креольский дрозд поёт всё лучше с каждым днём...» наиболее органично установке авторского мифа поэта на поиск самоидентификации. Данный поэтический текст посвящен легендарному аргентинскому певцу танго Карлосу Гарделю, 
что, видимо, становится для русского поэта-эмигранта признанием личностного значения культурного универсума Латинской Америки.

Креольский дрозд поёт всё лучше с каждым днём.

Бессонница. Гардель. Говядина на льдине.

В пространстве между мной и колумбийским дном

проносится июнь, как ветер в Медельине.

Шипит огонь. Шипит сквозь зубы патефон.

Шнуруя у окна высокие ботинки,

я путаю узль, когда мадам Ивонн,

качнув бедром, легко спускается с пластинки.

Она идёт. Ия, невидимый холуй,

скольжу за ней, как тень от факела Гекубы.

Гардель. Он так похож на грубый поцелуй,

что, стоя у перил, она кусает губы.

Балкон и танго. Ночь. Потёртый переплёт,

в котором я-Харон, приблудная гримаса-

готовлю для него последний самолёт

и жарю для неё божественное мясо ${ }^{1}$. [28]

По наблюдению Ю. Гирина, «мир Латинской Америки являет собой совокупность множества этнических, культурных, цивилизационных и формационных типов», где путем ассимиляции «инокультурные ценности претерпели и продолжают претерпевать такое перекодирование, что практически все «универсальные» категории культуры в новом контексте наполняются совершенно особыми смыслами, приобретают специфическую коннотацию» [5, с. 11-12]. А. Ширяев, попадая в Латиноамериканский мир, как русский поэт-эмигрант оказывается в ситуации продолжения традиций и в то же время поиска новых смысловых горизонтов, адекватных для авторской идентификации. Примечателен факт, что при эмиграции А. Ширяева в Эквадор для поэта представляют интерес разные ибероамериканские страны и города. Достаточно вспомнить его книгу стихов «Январская река»,

\footnotetext{
${ }^{1}$ Стихотворение опубликовано на сайте Андрея Ширяева 6 августа 2013 года, чуть больше двух месяцев до смерти поэта.
} 
своим названием отсылающая к топосу Рио-де-Жанейро, будучи переводом наименования легендарного бразильского города на русский язык. Не менее показателен ширяевский интерес к аргентинистике, соотносимый с феноменом танго, личностью Карлоса Гарделя и особой атмосферой Буэнос-Айреса - города эмигрантов и главного культурного центра Латинской Америки, прозванного Латиноамериканским Парижем. Выбор А. Ширяевым для самоидентификации буэнос-айресских мифологических топосов и персоналий показателен проявлением органичной погруженности в мир смешения традиций, рас, культур. Такой ракурс позволяет А. Ширяеву ощутить себя вполне полноценным гражданином Латиноамериканского мира - эмигрантского по своей природе, не утратив связи со своими корнями, русской культурой и поэтическим наследием, что акцентирует невозможность в ширяевском случае перехода на другой язык.

\section{3. Танго как эпистема аргентинской культуры}

Как поэт-эмигрант А. Ширяев подыскивает новый вид самоидентификации, который, помимо погруженности его сознания в универсум русской культуры, окажется подходящей моделью для самопознания и создания авторского мифа. Таким культурно-этническим модусом становится дискурс танго, представляющий, своего рода, аргентинскую эпистему.

Неравнодушие А. Ширяева к метатеме музыки вообще и интерес к феномену танго и к личности его легендарного исполнителя, помимо сильного семиотического потенциала, связанно и с биографической особенностью современного поэта: временной работой в консерватории и его выступлениями в качестве барда. Внимание к музыкальности и музыкальной мифологии в лирике А. Ширяева может иметь еще одно объяснение. Своеобразие поэтического мышления автора сопрягает различные метафоры, мотивы, мифологемы и мерцающие образы в лирический сюжет, неожиданный и даже парадоксальный. Такая специфика поэтического мышления обнажает музыкальность мировосприятия автора. По утверждению Ю. Степанова, «поэтика трагически ушедшего из жизни Андрея Ширяева максимально сложна и имеет $<\ldots>$ максимальный коэффициент тропонасыщенности» $[19$, с. 3]. Ярко выраженный метафорический потенциал лирики А. Ширяева является свидетельством близости авторскому сознанию 
поэта-эмигранта элементов мистериально-дионисийского дискурса. По наблюдению О. Ханзен-Лёве, «дионисийство перешагивает ограничения $<\ldots>$ реализует экстатические культы трансгрессии и регресии» [26, с. 137], проявляющиеся в потенциальной тяге к синтетизму, неосинкретизму и гибридности. Дионисийский модус с соответствующими доминантами экстаза и трансгрессивности во многом определил преемственность поэтического сознания А. Ширяева латиноамериканским эпистемам.

По мнению музыковеда П. А. Пичугина, «танго создало свой арсенал тем, сюжетов, мотивов, персонажей, не выдуманных, а “срисованных с натуры”. Танго выработало свои музыкальные и поэтические формы, свой стиль, язык, свою особую манеру выражения» [17, с. 9]. Несомненно, что доминантой сюжетов танго является своеобразная семиотика страстей, проявление эмоционального спектра кодируется мифологемами Буэнос-Айреса, духом столицы и портового города, в недрах которого смешаны, социальные классы, нации, культуры. Подобные трансгрессивность и пассионарность подразумевают потенциальную карнавальность и дионисийский дух, воплощенные в аргентинском танго.

Ю. Гирин отмечает, что уже «к 1920-м годам аргентинское национальное сознание обретает себя в такой форме праздничного ритуала, как танго с его ощутимо теллурической доминантой, которое навсегда сделалось эмблемой целой нации» [5, с. 69]. Торжество земной стихии и телесности, акцентированные Ю. Гириным, своего рода восприятие жизни как пира, находит в феномене танго слияние с трагичностью бытия, идеей рока и подчиненности человека страстям.

В данной связи вспоминается эссе Х. Л. Борхеса «История танго», где осмысляется природа танго через показатели любовной дуэли и веры «в бой как праздник» [3, с. 115]. С точки зрения Х. Л. Борхеса, «предназначение танго <курсив - C. $Ф$.>: внушить аргентинцам веру в их былую отвагу, в то, что однажды они нашли в себе силы не уклониться от требований доблести и чести» [3, с. 115].

Мысль Х. Л. Борхеса, окончательно вписывает культуру танго в парадигму страстей. Согластно убеждению аргентинского писателя, «музыка - это воля, страсть во всей их полноте. И старое танго по образу и подобию музыки - напрямую передает эту радость боя...» 
[3, с. 116]. Так аргентинское воспевание любовных страстей и поножовщины, весьма близкое к эстетике городского романса и традиции портовых песен, преображается не просто в пассионарную, но и героическую составляющую аргентинского духа.

Вопреки предпочтению Х. Л. Борхесом танго-мелодии, несомненно, для Аргентины танго как феномен национально-культурной идентичности - это, прежде всего, песни К. Гарделя. По мнению С. Бурини, «потребность в идентичности, рожденная социальными сдвигами в современном мире, приводит к тому, что фокусом современных интеллектуальных и научных дискуссий становится связь между памятью и идентичностью (индивидуальной и коллективной), между памятью и историей» $[4$, с. 71$]$. Согласно поэтической логике А. Ширяева, танго привлекательно как экспликация и личностных страстей, и феномен непосредственно связанный с жизнью легендарного исполнителя Карлоса Гарделя, давно в ибероамериканском восприятии превратившегося в миф.

Для верного понимания той степени любви и почитания личности «Креольского дрозда» аргентинским миром, достаточно вспомнить слова из эссе X. Кортасара «Гардель»: «Когда Гардель поет танго, стиль его пения - это истинно народный стиль, вот почему аргентинцы сделали его своим кумиром. < .. > В его голосе этакого бесшабашного портеньо, как в звучащем зеркале, отражается Аргентина, которая постепенно уходит из нашей памяти» [9, с. 61]. Как видно из приведенного фрагмента, для Аргентины К. Гардель не только легендарная личность, но и воплощение в реально существовавшем человеке национального архетипа. Аргентинский миф о Гарделе представляется утверждением величия Буэнос-Айреса, не раз воспетого портеньо - поющим танго, чья судьба и творчество обладают столь сильным мифогенным потенциалом. При этом Гардель становится своего рода знаком культурной идентификации, формирующей представления о доминантах не только аргентинской, но и общей латиноамериканской ментальности.

\section{4. «Семиотика страстей» в рамках лирического сюжета А. Ширяева}

В анализируемом поэтическом тексте смысловые пласты накладываются на интерпретацию фактов биографии Карлоса Гарделя в соот- 
ветствии с ширяевским мифом. Стихотворение начинается с прямой цитации аргентинской поговорки о креольском дрозде, подразумевающей пение Гарделем танго: «El Zorzal canta cada día mejor». Дальше упоминается Мадам Ивонн - героиня одноименной песни кумира Аргентины, запись которой в 1933 году, стала последней записью пластинки, сделанной в Буэнос-Айресе перед гастролями, после которых вернуться в город своей славы, ставший его истиной родиной, певцу было не суждено. Третьим опорным пунктом лирического сюжета становится гибель К. Гарделя в 1935 году в Медельине в авиакатастрофе из-за столкновения двух самолетов.

Песни-танго К. Гарделя воспринимаются аргентинским миром как самобытный вид «musica humana» - «музыки души». Представляя полифоническое единство из мелодии-танго, стихов и голоса Гарделя, эти музыкальные тексты становятся для эмоционально сопричастного слушателя вариантом диалога с культурной идентичностью, семиосферой страстей, исповедальным дискурсом. По слову А. Е. Махова «“музыка души” входила в словесное произведение <..> не извне, а изнутри, как его самая интимная тема или как принцип выразительности, действующий из самых потаенных глубин произведения» $[14$, c. 27]. Танго с упомянутой пластинки активизирует сферы интимности, пассионарности и самопознания. Образ поющего креольского дрозда, вступая в смысловой диалог с темой метаморфоз, позволяет обыгрывать амбивалентную символику этой птицы и тему божественного пения. Лирический герой ширяевского стихотворения, во время бессонницы, слушая исполнение К. Гарделем «Madame Ivonne», погружается в онерическое пространство, порождающее визию мифологического проживания полета и гибели К. Гарделя.

Согласно замечанию Х. Кортасара, «покрутить ручку граммофона, наставить иглу, похоже, это - непременное ритуальное действо, перед тем как услышать Гарделя» [9, с. 60]. Так в стихотворении А. Ширяева «звучащий патефон» возрождает погибшего в Медельине К. Гарделя. При этом по наблюдению Ю. Лотмана, «противопоставление “дома живых" и “антидома псевдоживых” осуществляется <...> с помощью целого набора устойчивых признаков, в частности освещения и звуковых характеристик. Так, например, из антидома слышатся звуки патефона» $[12$, с. 317]. В ширяевской поэтической интерпретации звуки 
пластинки, благодаря поэтической фантазии, позволяют материализоваться фантому мадам Ивонн и предстать вполне реальной и полнокровной женщиной, способной пробуждать сексуальное влечение («я путаю узль, когда мадам Ивонн, / качнув бедром, легко спускается с пластинки»). Эксплицируемые страсти сюжета песни-танго, ее ритма и звучания в рамках поэтического текста А. Ширяева переключаются на уровень семиотизации страстей мифологизирумых персонажей лирического дискурса.

Ширяевское стихотворение строится как своего рода парафраз культуры танго с опорой на доминантные мифологемы о культурном герое, с подчеркнутой страстностью лирического переживания. Процессы семиотизации страстей и поиска собственной идентичности соотвествуют моделируемому современным поэтом авторскому мифу о танго и гибели Карлоса Гарделя. С точки зрения авторов «Семиотики страстей», «во-первых, каковы бы ни были позиции партнеров, модальное устройство, характеризующее страсть <..> это вневременная константа, управляющая всем страстным взаимодействием. Во-вторых, варьирование позиций подчиняется строгим правилам и может превратиться в рассказ» [6, с. 309]. В ширяевском поэтическом дискурсе такой константой становится пассионарный характер танго, а «рассказом» - развитие лирического сюжета. Лирический сюжет А. Ширяева показателен тем, что текст посвящен Гарделю и в то же время певец танго оказывается поэтическим объектом в противоположность лирическому субъекту («я»), отождествляющемуся с личностью русского поэта-эмигранта. В качестве героини в ширяевский поэтический текст вводится образ мадам Ивонн, предстающей в ипостасях: фантома - возлюбленной - судьбы - демониць - божества.

\section{5. Поэтизация образа femme fatale как анимы лирического субъекта}

Мифогенная сущность мадам Ивонн обусловлена ее фантомной реализацией как персонажа одноименного танго, записанного К. Гарделем накануне гибели, и как героини стихотворения русского поэтаэмигранта. Подобная призрачность придает в поэтической фантазии А. Ширяева героине статус демоничности, тотемности, даже языческой божественности. Р. Барт, осмысляя феномен лица Греты Гарбо, 
отражающего образ роковой женщины своей эпохи, определил его как лицо-маску, воплощающее архетип, идею. Согласно мысли выдающегося французского семиолога такое лицо «связано с <..> царством куртуазной любви, где живая плоть порождает мистические чувства погибели» [1, с. 133]. По мнению Р. Барта - это с семиотической точки зрения «лицо тотема с растительно-темными глазами» [1, с. 133], своеобразное переходное явление, когда «священный ужас сменяется очарованием» [1, с. 134-135]. Концентрацией подобных чувств и страстей становится в ширяевской интерпретации мадам Ивонн, существующая лишь благодаря голосу Карлоса Гарделя. В то же время факт грамзаписи и прослушивание пластинки лирическим героем оживляет воспоминания о великом певце танго. Страстное влечение к фантомной героине, обретающей телесность («качнув бедром»), придает ощущение подлинности лирическому переживанию, отражающему авторский миф поэта-эмигранта.

Тема страсти решается в ширяевской интерпретации разнопланово. Интенсивность и экспрессия чувства материализует призраков: погибшего Гарделя, мадам Ивонн. Возникает фантазия об эротическом влечении: мадам Ивонн к Гарделю, лирического героя к ней. Третий пласт составляет тема желания поедания, соотносимая с женским образом («кусает губы»). Лирическому герою отводится роль быть инструментом судьбы в приготовлении жертвоприношения.

Ожившая мадам Ивонн благодаря игровой стратегии А. Ширяева из героини песни Гарделя превращается в его вполне реальную возлюбленную - этакую femme fatale и даже своего рода «вдову» аргентинского кумира. Эту позицию можно охарактеризовать формулой, предложенной О. Матич для описания декадансного искусства, но вполне соответствующей и ширяевскому лирическому сюжету. По слову О. Матич, «обнаруживается одержимость мифологическим прошлым, стилизованным в виде сцены, часто помещенной в экзотическое пространство, в котором femme fatale разыгрывает свое кастрационное эротическое влечение» [13, с. 99]. Упоминание одного из понятий психоанализа - комплекса кастрации, подчеркивает доминантность женской роли, интенсивность ее эротического потенциала, формирующего имидж и модель поведения роковой женщины, несущей разрушение. Такому мифологизированному типу женственности 
оказывается, априорно присуща демоничность и призрачность, ведь «эротизированный женский образ декаданса, созданный художником, символизирует жизнь и смерть одновременно» [13, с. 99]. В ширяевской версии женский фантом предстает воплощением влекущей, гибельной сексуальности. Лирический герой подчиняется роковым чарам мадам Ивонн. Но в противоположность подчеркнутой мужественности Гарделя («Гардель. Он так похож на грубый поцелуй»), с лирическим «я» - альтер эго автора, соотносится некая мазохистски маркированная позиция любящего: «я, невидимый холуй», «скольжу за ней, как тень», «приблудная гримаса», «и жарю для неё божественное мясо». А. Ширяев подчеркивает свою позицию постороннего, обыгрывая дистанцирующую роль автора текста. При этом субъект, продуцируя поэтический дискурс, сам становится героем и движущей силой развертываемого лирического сюжета.

Фантом - мадам Ивонн, фантазийно воплощает сексуальность и предчувствие эротического переживания. Желая Гарделя, опьяненная музыкой танго, «она кусает губы», что выдает интенсивность ее влечения, эротические стремления - даже симуляцию поцелуя, предвкушение поглощения. По мысли Ж. Старобинского, «женщина-разрушительница $<\ldots>$ соединяет в себе оба аспекта той перверсивной роли, которую воображение зрителя склонно проецировать на актрису, - активный и пассивный» [18, с. 529]. Соотношение подчеркнутой и даже театрализированной эротичности мадам Ивонн, при фантазмном характере ее ипостаси, позволяет выявить в этом женском образе не только демонические коннотации, но и обратить внимание на символический потенциал чувственного начала, олицетворяемого героиней.

В данном плане показательна идея Д. Иоффе, что «символистский эрос имел самое непосредственное отношение к феномену жизнетворчества» [8, с. 255]. Для А. Ширяева - поэта, по времени принадлежащего скорее постмодернистской и метамодернистской эпохам, но при этом укорененного в эстетические поиски Серебряного века, привлекательно модифицировать символистский феномен жизнетворчества, вмонтировав его в свое поэтическое сознание как опыт познания себя в мире. Так «...чувственное начало активизирует $<\ldots>$ для авторского сознания широкое смысловое поле с высокой степенью 
мифогенности» [22, с. 282]. Неожиданный акцент на образе мадам Ивонн, позволяет А. Ширяеву создать авторскую версию мифа о Гарделе, подчеркнув трагический и даже гибельный характер, воплощенный в героине-фантоме. В лирическом сюжете современного поэта представлена символическая перспектива призрачной, но роковой чувственности, что позволяет обыгрывать демонические, но, в то же время, идеализированные черты женского образа. Чары мадам Ивонн предстают метафорой трагической судьбы Гарделя, а на более глубинном уровне и авторского «я».

Статус языческого божества, с которым соотносится в поэтической фантазии А. Ширяева мадам Ивонн, акцентирует не только ее амбивалентность как анимы, не менее важна и авторская фиксация трансгрессивности. По наблюдению американской исследовательницы $\mathrm{X}$. Эйзенфелд, именно богиня подземного мира, такая как греческая Персефона, «способствует соприкосновению экзистенциалов жизни и смерти, своим присутствием разрушая границу между мирами человеческого и божественный опыта» [29, с. 15]. Трангрессивный контекст, соотносимый с женский образом в стихотворении, акцентирует мотивы перехода: между жизнью и смертью, реальностью и фантазией, образом Гарделя и лирическим героем - ширяевским альтер эго, наконец, между культурным наследием прежней родины А. Ширяева и мифологемами Латиноамериканского мира.

В поэтической фантазии А. Ширяева мадам Ивонн своей фантомностью уподобляется Лилит, предстающей суккубом-обольстительницей, воплощением роковой женственности и в то же время призраком. Сближает с Лилит и особенности наименования героини - «мадам Ивонн», ассоциативно созвучное с одним из имен демоницы - «Фрау Венера», встречающимся в немецко-еврейском фольклоре. Тема поедания также активизирует в женском образе демоническое начало. В словаре демонологии под редакцией А. Е. Махова, представлена традиция согласно которой демон-суккуб Лилит сближается с Ламией. Более того, ламии «подстрекают молодых людей вступать с ними в телесное общение, после чего юноши истощают силы в распутстве, они сжирают их» $[15$, с. 231]. Так мадам Ивонн, возникшая благадаря песне Гарделя, подобно Лилит, обольщая лирического героя, готова поглотить его, как и своего создателя - легендарного певца танго. 
В ширяевской поэтической фантазии мадам Ивонн, как подобает аниме согласно юнгианской концепции, обладает двойственной природой. Позитивная, сакрализированная ипостась наделяется возвышенной природой, воплощающей стремление к свету и одухотворенности. Другой стороной архитипической женской амбивалентности представляется темное, разрушительное, хтоническое начало. Подобное соотношение, согласно К. Богданову, показательно для случая Сфинги, загадывающей загадку Эдипу и пожирающей тех, кто не смог дать ответ. Так Сфинга символически эксплицирует «инаковость природной стихии» [2, с. 237] в человеческом «я». По мнению исследователя, «загадочность монструозного уравнивается в данном случае с загадочностью конституирующего себя человеческого “я”, не способного избавиться от субъектьивно-инакового в себе» [2, с. 237]. Статус анимы лирического героя придает философский аспект демоническому ореолу мадам Ивонн. Мадам Иванн предстает аналогом музы и спутницы лирического «я», унаследованной им от легендарного Гарделя и тем самым вносящей в его жизнь не только вдохновение, но и гибельный характер. Имплицитно акцентируя в женском персонаже черты ламии, А. Ширяев обыгрывает несколько принципиально важных тем. Вполне античная тема рока, нависшего над поэтом, предстает не только в качестве метафоры, но и находит соответствия непосредственно в трагической тональности ширяевской биографии. Не менее значимо и представление о неоднозначности своего человеческого «я», не лишенного парадоксальности и теневых сторон, которые подчеркивает образ возлюбленной-ламии как женского воплощения альтер эго героя.

А. Ширяев поливалентно моделирует женский образ-призрак, так что мадам Ивонн возможно воспринимать и как демоницу, и как воплощение влюбленности и непосредственности. Героиня оказывается сама зачарованной, а ее жизненный цикл совпадает с вращением диска пластинки с записью голоса Гарделя.

\section{6. Символические контексты метафоры пожирания}

Тема огня объединяет различные смысловые пласты лирического сюжета А. Ширяева, эмблематически маркируя коды страсти, приготовления, а с мифологической точки зрения - культуры. Огонь в 
контексте представлений о танго становится и его символической заменой: «Шипит огонь. Шипит сквозь зубы патефон». Метафора, описывающая звучание пластинки, показательна тем, что акцентирует образ зубов, который получает лейтмотивное решение в ходе развития ширяевского лирического сюжета: «что, стоя у перил, она кусает губы», «и жарю для неё божественное мясо». Смысловые пласты, соотносимые со значениями, связанными с понятием зубов, позволяют эксплицировать тему сексуального желания, при этом модифицируя в представление о плотоядности.

По наблюдениям К. Леви-Стросса существует «введенная мифом инверсия эротической связи <..> объектом ее являются либо мед, либо мясо» [11, с. 139]. Более того, французский антрополог приводит различные варианты мифа индейцев, где муж жарит мясо убитого любовника и заставляет жену его съесть. Такой возможный канибалический подтекст («и жарю для неё божественное мясо») в ширяевском стихотворении может прочитываться как своеобразная философская метафора страсти-поглощения. Не менее показательна мысль К. Леви-Стросса, что «растительная гниль относится к природе, приготовленное мясо - к культуре» [11, с. 152]. Тема жаренного на огне мяса манифестирует утверждение культурного универсума, который для Аргентины, а шире для всего латиноамериканского мира, символизирует в определенной степени Гардель.

Подчеркнутая сексуальность мадам Ивонн дополняется трансформацией эротических кодов в коды гастрономические. С точки зрения психоанализа поглощение представляется процессом, «посредством которого субъект в своих фантазиях», съедая объект, «сохраняет его в себе. $<\ldots>$ Это телесный прообраз интроекции и самоотождествления» [10, с. 164]. Фантазийно-канибалистский контекст ширяевского стихотворения можно декодировать согласно стратегиям психоаналитического дискурса в виде воображаемых аспектов, проявляющихся как «любовь, разрушение, сохранение в Я, присвоение качеств объекта» $[10$, с. 190]. А. Ширяев моделирует ситуацию, в которой лирическое «я» уподобляется Гарделю в его мифологизированном и мифогенном статусе.

3. Фрейд в работе «Тотем и табу» отмечает, что «вбирая в себя части тела какого-нибудь лица посредством акта пожирания, усваи- 
вают себе также и свойства, которые имелись у этого лица» [25, с. 78]. Аллюзия поедания плоти сгоревшего Гарделя обыгрывает вампирическое амплуа женского персонажа и тему преображения: смена ролей и обретение телесности призраком.

В ширяевской поэтической фантазии метафора людоедства реализуется практически буквально как возможность поедания мадам Ивонн «плоти» сгоревшего Гарделя («И жарю для нее божественное мясо»). Такой аспект высвечивает в героине демонические коннотации, акцентируя тему вампиризма. В то же время «вдовство» героини символически реализует ее желание воссоединения с Гарделем, аналогично страсти лирического героя к роковой женщине-фантому. По мнению Т. Михайловой и М. Одесского, «стремление обрести возлюбленную описывается посредством проекции как ее собственное желание воссоединиться с героем. Подвидом сюжета о жене из Иного мира может быть назван фольклорный мотив о расколдовывании девушки, временно (или от рождения) попавшей во власть сил тьмы» [16, с. 135]. Аналогичная ситуация, обыгрываемая в подтексте лирического сюжета А. Ширяева, позволяет интерпретировать стремление лирического героя униженно служить мадам Ивонн и необходимость переживать трагическую гибель Гарделя, даже чувствовать себя ее соучастником («готовлю для него последний самолет»), как потенциальную возможность расколдовывания аргентинской версии Незнакомки.

Трагическая гибель Гарделя, разбившегося на самолете в Медельине, в конце стихотворения предстает преддверием поедания певца мадам Ивонн, видимо, волей автора предстающей неким божеством, алчущим жертвоприношений («и жарю для неё божественное мясо»). По утверждению В. Топорова, еда «в мифах связана со всеми тремя элементами комплекса смерть-плодородие-жсизнь и жертвоприношением, в котором мистерия смерти, гибели путём расчленения, разъятия частей, размельчения должна вызвать состояние плодоносящего изобилия...» [20, с. 427]. Так гибель кумира Латинской Америки осмысляется в лирическом сюжете А. Ширяева как сакральный акт сожжения героя на огне. При этом в решении А. Ширяева канибалические аллюзии центрируются стремлением навсегда неразделимо соединиться с объектом неистовой любви всего латиноамериканского мира. 
Показательно, что в ширяевском «стихотворении, посвященном К. Гарделю, явно просматриваются интертекстуальные переклички» $[23$, с. 178$]$ с поэтической культурой Серебряного века. Одной из таких наиболее очевидных аллюзий является отсылка к знаменитому стихотворению О. Мандельштама. Реминисценции мандельштамовского стихотворения «Бессонница. Гомер. Тугие паруса...» в поэтическом дискурсе А. Ширяева проявляются как трансформации темы журавлиного клина в полет Гарделя в Медельин, Елены Троянской в образ роковой и притягательной мадам Ивонн, мотива шума моря и грохота в аллюзию авиакатастрофы, в которой гибнет Гардель. А. Ширяев не только использует искаженную цитату-заглавие мандельштамовского стихотворения, но и переосмысляет ряд его мотивов, моделируя, таким образом, подтекстовый пласт своего лирического сюжета. Общая для обоих поэтических текстов тема бессонницы, но в ширяевском варианте вместо Гомера фигурирует Гардель. Такая переориентировка не случайна и означает установку на разнонаправленный диалог, признак дионисийского дискурса. При этом замена Гомера Гарделям знаменует необходимую А. Ширяеву смену ориентиров для авторского сознания, особенно в процессе идентификации.

\section{7. Метаморфозы как мифологизированные стратегии идентификации}

Упоминанием звучания патефона с играющей на нем пластинкой активизируется тема метаморфоз, решаемая А. Ширяевым вполне в дионисийском ключе. По замечанию Е. Фарино, «... озвучение $-<\ldots>$ одно из многих проявлений $<\ldots>$ овнешнения» [21, с. 280] потаенных чувств, воскрешая «древнейшие представления о звучащем бытии всего сущего» [21, с. 319]. Воспоминание о кумире Аргентины и его судьбе, вызванное звуками танго «Madame Ivonne», мифологически возрождает бытие певца в преддверии грядущей гибели. Так из призрака Гардель, благодаря грезам лирического героя, превращается в мифологическую жертву, обретая божественность. Метаморфозы, причем мгновенные, связываются с постоянным изменением статуса не только Гарделя, но также мадам Ивонн и лирического героя («невидимый холуй», «тень от факела Гекубыл», «Харон, приблудная гримаса»). 
Вышеописанные трансформации на уровне подтекста способствуют смысловым приращениям и развитию лирического сюжета. Центром, активизирующим процесс метаморфоз в поэтическом тексте поэта-эмигранта становится образ дрозда из аргентинской поговорки (El Zorzal canta cada día mejor), подразумевающей исполнение танго К. Гарделем. С точки зрения Т. Цивьян, именно птица, наделенная способностью летать и петь, в мифологической картине мира, осуществляет связь между посюсторонним и потусторонним мирами. Т. Цивьян отмечает, что помимо отождествления с полетом души, оставившей тело, эти «два признака - крылья / полет и голос / речь - и являются определяющими в “назначении” птицы связным между верхним и нижним мирами» [27, с. 273]. Так образ дрозда («Креольский дрозд поёт всё лучше с каждым днём») объединяет смысловой ряд стихотворения, важный для моделирования авторским сознанием А. Ширяева мифологического потенциала лирического сюжета. Этот аспект поэтической наррации, дополняемый паратекстульными ассоциациями, схематически можно представить следующим образом: птица - пение - полет - икарийский комплекс божественность / демоничность (в зависимости от цвета оперения) еда (пирог с дроздами).

Метаморфоза превращения Гарделя в дрозда, ассоциативное соотнесение с закланием тельца, акт жертвоприношения - жареное «божественное мясо», завершается обретением возрождения и бессмертия. Гардель в мифологическом смысле предстает жертвой, что запускает механизм сакрализации. С точки зрения С. Зенкина, обретение сакральности соответствует двум этапам прохождения ритуала: жертвоприношение, сменяющееся обретением божественности, в семиотическом плане предстает как «сложная игра подмен и “неузнаваемых” ритуально-мифологических превращений» [7, с. 229]. Статус жертвы активизирует в ширяевском поэтическом тексте дионисийский комплекс и соответствующие потенциалы трагичности, трансгрессивности, метафоричности. Народная любовь к Гарделю в сердцах слушателей на мифологическом уровне реализуется причащением его плотью - в подтексте записанными им при жизни танго.

Обыгрывая события гибели «Креольского дрозда» как заключительный этап метаморфозы, лирический герой вынужден сле- 
довать за логикой трагических событий и не в силах что-либо в их ходе изменить. Перформативность поэтического слова вызывает из небытия призрак мадам Ивонн, превращает ее в живую женщину, а после - в божество. Гардель становится знаком близости латиноамериканской эпистемы для эмигрировавшего в Эквадор русского поэта, также переживающего процесс превращения в плане стратегий идентификации.

\section{8. Результаты исследования}

Поэтическая фантазия А. Ширяева о Гарделе не только интерпретирует аргентинские мифологемы, но и становится значимым дополнением авторского мифа поэта. Доминантами игровой идентификации поэта-эмигранта выступают дискурс танго, эротизация образа изначально фантомной героини, а главное, поэтическое «оплакивание» гибнущего легендарного певца - культурного героя Аргентины.

\section{9. Выводы}

Эпистемы аргентинской культуры, включая общие ментальные тенденции латиноамериканского этоса, вступают в диалог со стихотворением А. Ширяева о Гарделе, формируя подтекстовый уровень, который в то же время становятся чем-то вроде авторского комментария-подстрочника. Трансгрессивный потенциал образной системы поэтической фантазии русского поэта о Гарделе можно объяснить рядом факторов. С одной стороны близостью дионисийскому типу мироощущения, дающего установку на полифоничность и музыкальность. С другой - потенциальной пограничностью авторского сознания поэта-эмигранта. Ширяевский поэтический миф определяет нахождение как непосредственно авторского, так и лирического «я» на пересечении культуры русской, европейской и латиноамериканской с характерным набором различных мифологем, образов, интертекстов. Поиск А. Ширяевым в аргентинском эпистемологическом наследии путей для новой самоидентификации, органичных дионисийскому дискурсу, направлен на одновременное принятие нового и утверждение своей укорененности в традиции русской литературы. 


\section{Список литературы:}

1. Барт Р. Мифологии. Москва : Академический проект, 2008. 351 с.

2. Богданов К. А. Повседневность и мифология. Санкт-Петербург : Азбука, Азбука-Аттикус, 2015. 416 с.

3. Борхес Х. Л. История танго: [эссе]; [пер. с исп. Б. Дубина]. Собр. соч.: 8 4 m. Т. 1. / [под ред. Б. Дубина]. Санкт-Петербург : Амфора, 2011. С. 115-118.

4. Бурини С. Культурная память как семиотический механизм в искусстве. Память как объект и инструмент искусствознания / [сост. Е. А. Бобринская, А. С. Корндорф]. Москва: Государственный институт искусствознания, 2016. С. 70-79.

5. Гирин Ю. Н. Латинская Америка: культура инаковости. Москва : Государственный институт искусствознания, 2019. 276 с.

6. Греймас А. Ж., Фонтаний Ж. Семиотика страстей. От состояния вещей к состоянию души. Москва : ЛКИ, 2007. 336 с.

7. Зенкин С. Небожественное сакральное: Теория и художественная практика. Москва : РГГУ, 2012. 537 с.

8. Иоффе Д. К вопросу об эротическом субстрате феномена модернистского жизнетворчества: случаи Блока и Хармса. Моделирование текстов жизни и текстов поэзии. Дискурсы телесности и эротизма в литературе и культуре: Эпоха модернизма: [сб. ст.] / [под ред. Д. Г. Иоффе]. Москва : Ладомир, 2008. С. 241-299.

9. Кортасар Х. Гардель: [эссе]; [пер. с исп. А. Брагинской]. «Я играю всерьез...». Москва : Академический проект, 2002. С. 58-61.

10. Лапланш Ж., Понталис Ж.-Б. Словарь по психоанализу; [пер. с франц. Н. С. Автономовой]. Москва : Высш. шк., 1996. 623 с.

11. Леви-Стросс К. Мифологики: в 4 т. Т. 2.: От мёда к пеплу. Москва; Санкт-Петербург : Университетская книга, 2000. 442 с.

12. Лотман Ю. М. Внутри мыслящих миров. Семиосфера. СанктПетербург : Искусство - СПБ, 2004. С. 150-390.

13. Матич О. Покровы Саломеи: Эрос, смерть и история ; [авториз. пер. с англ. О. В. Карповой]. Эротизм без берегов : [сб. статей и материалов] / [сост. М. М. Павлова]. Москва : НЛО, 2004. С. 90-121.

14. Махов А. Е. Musica literaria. Идея словесной музыки в европейской поэтике. Москва : Intrada, 2005. 224 с.

15. Махов A. E. Hostis antiquus: Категории и образы средневековой христианской демонологии. Опыт словаря. Москва : Intrada, 2006. 416 с.

16. Михайлова Т. А., Одесский М. П. Граф Дракула: опыт описания. Москва : ОГИ, 2009. 208 с.

17. Пичугин П. А. Аргентинское танго. Москва : Музыка, 2010. 279 с.

18. Старобинский Ж. Портрет художника в образе паяца. Поэзия и знание: История литературы и культуры: в 2 т. Т. 2. Москва : Языки славянской культуры, 2002. С. 501-581.

19. Степанов Ю. Выдающийся поэт Андрей Ширяев: [предисловие к изданию]. Ширяев А. В. Случайный ангел. Москва : Издательство Евгения Степанова, 2016. 60 c. 
20. Топоров В. Н. Еда. Мифы народов мира: в 2. т. Т. 1. : А-К / [глав. ред. С. А. Токарев]. Москва : Советская Энциклопедия, 1991. С. 427-429.

21. Фарино Е. Введение в литературоведение. Санкт-Петербург : Издательство РГПУ им. А. И. Герцена, 2004. 639 с.

22. Фокина С. А. Интерпретация танго как музыки страсти в поэтической фантазии Андрея Ширяева о Гарделе. Мова і культура. Київ : Видавничий дім Дмитра Бураго, 2018. Вип. 21. Т. V (194). С. 278-286.

23. Фокина С. А. Диалог с Серебряным веком в «аргентинском» лирическом сюжете поэта-эмигранта А. Ширяева. К вопросу об «апокалиптической» поэтике. Проблеми сучасного літературознавства. 2018. Вип. 27. С. 176-186.

24. Фокина С. А. Процессы сакрализации и демонизации в «мистериальном» лирическом сюжете поэта-эмигранта Андрея Ширяева. Annales Universitatis Paedagogicae Cracoviensis. № 295: Studia Russologica XII. Krakow : Copiright Wydawnictwo Naukowe, 2019. C. 108-119.

25. Фрейд 3. Тотем и табу. Психология первобытной культуры и религии; [пер. с нем. М. В. Вульф]. Харьков : Фолио, 2009. 157 с.

26. Ханзен-Лёве О. А. Интермедиальность в русской культуре: От символизма к авангарду. Москва : РГГУ, 2016. 450 с.

27. Цивьян Т. В. Птицы-курьеры. Мотив связи верхнего и нижнего мира в балканской перспективе. Язык: тема и вариации: в 2 кн. Кн. 1 : Балканистика. Москва : Наука, 2008. С. 271-279.

28. Ширяев А. «Креольский дрозд поёт всё лучше с каждым днём...». Мастер зеркал - поэзия и проза. URL: http://www.shiryaev.com/kreolskij-drozdpoyot-vsyo-luchshe-s-kazhdym-dnyom/

29. Eisenfeld H. Life, Death, and a Lokrian Goddess. Revisiting the Nature of Persephone in the Gold Leaves of Magna Graecia. Kernos. Revue internationale et pluridisciplinaire de religion grecque antique. № 29. 2016. Varia. P. 1-29.

\section{References:}

1. Bart R. (2008). Mifologii [Mythologies]. Moscow: Akademicheskij proekt. (in Russian)

2. Bogdanov K. A. (2015). Povsednevnost' $i$ mifologija [Everyday life and mythology]. St. Petersburg: Azbuka, Azbuka-Attikus. (in Russian)

3. Borhes H. L. (2011). Istorija tango: jesse [Tango history: essay]. Sobr. soch.: $v 4$ t. T. 1. [Collection of works in 4 vols. Vol. 1]. St. Petersburg: Amfora, pp. 115-118.

4. Burini S. (2016). Kulturnaja pamjat kak semioticheskij mehanizm v iskusstve [Cultural memory as a semiotic mechanism in art]. Pamjat kak obekt $i$ instrument iskusstvoznanija [Memory as an object and an instrument of art science]. Moscow: Gosudarstvennyj institut iskusstvoznanija, pp. 70-79.

5. Girin Ju. N. (2019). Latinskaja Amerika: kultura inakovosti [Latin America: culture of infidelity]. Moscow: Gosudarstvennyj institut iskusstvoznanija. (in Russian)

6. Grejmas, A. Zh. and Fontanij, Zh. (2007). Semiotika strastej. Ot sostojanija veshhej $k$ sostojaniju dushi [Semiotics of passions. From a condition of things to state of mind]. Moscow: LKI. (in Russian) 
7. Zenkin, S. (2012). Nebozhestvennoe sakralnoe: Teorija i hudozhestvennaja praktika [Not divine sacral: Theory and art practice]. Moscow: RGGU. (in Russian)

8. Ioffe D. (2008). K voprosu ob jeroticheskom substrate fenomena modernistskogo zhiznetvorchestva: sluchai Bloka i Harmsa. Modelirovanie tekstov zhizni i tekstov pojezii [On the issue of the erotic substrate of the phenomenon of modernist vitality: the cases of Block and Harms. Modeling of life texts and poetry texts]. Diskursy telesnosti i jerotizma v literature $i$ kulture: Jepoha modernizma [Discourses of physicality and eroticism in literature and culture: The era of modernism]. Moscow: Ladomir. pp. 241-299.

9. Kortasar H. (2002). Gardel: jesse [Gardel: essay]. "Ja igraju vserez...» [«Im playing seriously...»]. Moscow: Akademicheskij proekt, pp. 58-61.

10. Laplansh Zh. and Pontalis Zh.-B. (1996). Slovar po psihoanalizu [Dictionary on psychoanalysis]. Moscow: Vyssh. shk. (in Russian)

11. Levi-Stross K. (2000). Mifologiki: v 4 t. [Mythologiques: in 4 vols.]. Vol. 2.: Ot mjoda k peplu [From honey to ash]. Moscow; St. Petersburg: Universitetskaja kniga. (in Russian)

12. Lotman Ju. M. (2004). Vnutri mysljashhih mirov [Inside thinking worlds]. Semiosfera [Semiosphere]. St. Petersburg: Iskusstvo - SPB, pp. 150-390.

13. Matich O. (2004). Pokrovy Salomei: Jeros, smert i istorija [Veils of Salome: Eros, death and history]. Jerotizm bez beregov [Eroticism without banks]. Moscow: NLO, pp. 90-121.

14. Mahov A. E. (2005). Musica literaria. Ideja slovesnoj muzyki v evropejskoj pojetike [Musica literaria. The idea of verbal music in European poetics]. Moscow: Intrada. (in Russian)

15. Mahov A. E. (2006). Hostis antiquus: Kategorii i obrazy srednevekovoj hristianskoj demonologii. Opyt slovarja [Hostis antiquus: ategories and images of medieval Christian demonology. Dictionary experience]. Moscow: Intrada. (in Russian)

16. Mihajlova T. A. and Odesskij M. P. (2009). Graf Drakula: opyt opisanija [Count Dracula: experience of description]. Moscow: OGI. (in Russian)

17. Pichugin P. A. (2010). Argentinskoe tango [Argentine tango]. Moscow: Muzyka. (in Russian)

18. Starobinskij Zh. (2002). Portret hudozhnika v obraze pajaca [Portrait of the artist in the image of a jester]. Pojezija $i$ znanie: Istorija literatury $i$ kultury: $\mathrm{v}$ 2 t. [Poetry and Knowledge: History of Literature and Culture: in 4 vols.]. Vol. 2. Moscow: Jazyki slavjanskoj kultury, pp. 501-581.

19. Stepanov Iu. (2016). Vydaiushchiisia poet Andrei Shiriaev: (predislovie $k$ izdaniiu) [Outstanding poet Andrey Shiryaev: (the preface to the edition)], Shiriaev A. V. Sluchainyi angel [Shiryaev A. V. Random angel]. Moscow: Izdatelstvo Evgeniia Stepanova, pp. 3-5.

20. Toporov V. N. (1991). Eda [Food]. Mify narodov mira: v 2. t. [Myths of the peoples of the world: in 2 vols.] T. 1. [Vol. 1]: A-K. Moscow: Sovetskaja Jenciklopedija, pp. 427-429.

21. Faryno E. (2004). Vvedenie v literaturovedenie [Introduction to literary criticism]. St. Petersburg: Izdatelstvo RGPU im. A. I. Gercena. (in Russian) 
22. Fokina S. A. (2018). Interpretation of a tango as passion music in poetic imagination of Andrey Shiryaev about Gardel [Interpretation of tango as passion music in Andrei Shiryaevs poetic fantasy about Gardel]. Mova $i$ kultura [Language and culture], vol. 21/5, pp. 278-286.

23. Fokina S. A. (2018). Dialog s Serebrjanym vekom v «argentinskom» liricheskom sjuzhete pojeta-jemigranta A. Shirjaeva. K voprosu ob «apokalipticheskoj» pojetike [Dialogue with the Silver Age in the «Argentinean» lyrical plot of the emigrant poet A. Shiryaev. To the question of «apocalyptic» poetics]. Problemi suchasnogo literaturoznavstva [Problems of accidental literature], vol. 27, pp. 176-186.

24. Fokina S. A. (2019). Processy sakralizacii i demonizacii v «misterialnom» liricheskom sjuzhete pojeta-jemigranta Andreja Shirjaeva [The processes of sacralization and demonization in the «mysterious» lyrical plot of the emigrant poet Andrei Shiryaev]. Annales Universitatis Paedagogicae Cracoviensis. № 295: Studia Russologica HII. Krakow: Copiright Wydawnictwo Naukowe, pp. 108-119.

25. Frejd Z. (2009). Totem i tabu. Psihologija pervobytnoj kultury $i$ religii [otem and taboo. Psychology of primitive culture and religion]. Kharkov: Folio. (in Russian)

26. Hanzen-Ljove O. A. (2016). Intermedialnost v russkoj kulture: Ot simvolizma $k$ avangardu [Intermediality in the Russian culture: From symbolism to avant-garde]. Moscow: RGGU. (in Russian)

27. Civjan T. V. (2008). Pticy-kurery. Motiv svjazi verhnego i nizhnego mira $v$ balkanskoj perspektive [Courier birds. The motive for connecting the upper and lower worlds in the Balkan perspective]. Jazyk: tema $i$ variacii: v 2 kn. [Language: theme and variations: in 2 vols.]. Kn. 1: Balkanistika [vol. 1: Balkanistics]. Moscow: Nauka, pp. 271-279.

28. Shirjaev A. "Kreolskij drozd pojot vsjo luchshe s kazhdym dnjom...» ["The Creole thrush sings better and better every day...": lyric poem]. Available at: http://www.shiryaev.com/kreolskij-drozd-poyot-vsyo-luchshe-s-kazhdym-dnyom/

29. Eisenfeld H. (2016). Life, Death, and a Lokrian Goddess. Revisiting the Nature of Persephone in the Gold Leaves of Magna Graecia. Kernos. Revue internationale et pluridisciplinaire de religion grecque antique. № 29. Varia. P. 1-29. 